\title{
Alteridade radical: implicaçôes para o cuidado em saúde
}

| 'Liliane Brandão Carvalho, 2José Célio Freire, ${ }^{3}$ Maria Lúcia Magalhães Bosi |

Resumo: Este artigo pretende discutir ética e cuidado, sua mútua relação e algumas implicações desses termos na práxis dos profissionais atuantes no espaço dos serviços públicos de saúde. Para tanto, recuperam-se as contribuições de Emmanuel Lévinas nas quais se focaliza a ética da alteridade radical. Essa discussão nos parece oportuna como subsídio para um entendimento mais abrangente e denso das práticas desenvolvidas neste lócus específico de prática em saúde, visando à (re)construção de sujeitos ético-políticos, a partir da dimensão da escuta ética do cuidado para com o outro: no caso em questão, os usuários dos serviços.

> Palavras-chave: ética; Lévinas; cuidado; Saúde Coletiva; profissionais de saúde.
1 Psicóloga; Mestre em
Psicologia pela Universidade
Federal do Ceará - Professora
da Universidade de Fortaleza.

2 Psicólogo; Doutor em
Psicologia; Professor Adjunto,
Departamento de Psicologia/
Universidade Federal do Ceará.
Endereço eletrônico:
jcfreire@ufc.br.

${ }^{3}$ Psicóloga; Doutora em Saúde
Pública; Professora Associada;
Doutorado em Saúde Coletiva/
Faculdade de Medicina/
Universidade Federal do Ceará. 


\section{Introdução}

Falar em ética pressupõe uma alusão à moral, haja vista ambas as expressões estarem relacionadas a costumes aceitos e consagrados, ao consuetudinário. Contudo, enquanto o campo moral assume, grosso modo, o sentido de um conjunto de regras adquiridas por hábitos, o domínio da ética se vincula à assunção de uma posição ante a moral, ou seja, a constituição de uma morada. Desse modo, é possível compreender e distinguir esses campos, os quais existem em toda e qualquer sociedade, operando demarcações entre o que se concebe como certo e errado.

Consoante Mezan (1996), a ética é por natureza reflexiva, organiza-se em discurso, move-se no plano dos conceitos e argumentos e exige uma fundamentação. A moral, por sua vez, revela-se como elemento central ao convívio social, às questões da coletividade, sendo inseparável da necessidade de julgamento e de normatização, tanto das nossas ações quanto das de outros indivíduos. Assim, ao nos referirmos às implicações da vida em sociedade ou à entrada em cena do outro e aos questionamentos quanto aos princípios que orientam ações morais, já estamos no âmbito da ética, dimensão relacionada ao momento no qual nosso discurso ou nossas ações têm consequências para o outro, de forma direta ou indireta. Ética será entendida, portanto, no escopo deste estudo, para além da sistematização das normas, dos padrões de conduta ou dos conhecimentos objetivos acerca do comportamento humano prescritas em códigos de ética ou outros dispositivos.

Importa assinalar que não há ética sem o outro, sem sua entrada em cena (ECO, 2000), pois o que falamos e fazemos tem ressonância e acaba influenciando na produção de verdades sobre o outro. A dimensão da ética não pode, assim, ser pensada de forma abstrata, nem se limitar aos juízos prescritos ou normativos da sociedade. Ela é da ordem do "real", ou seja, das relaçôes concretas produzidas nos, e a partir dos, encontros intersubjetivos, em dado contexto sócio-histórico, sendo mais condizente com a exigência de uma constante reflexão crítica - de um por-em-questão as normas e padrões estabelecidos - e com uma contínua avaliação do sentido e dos fins de uma ação.

Intrinsecamente ligada às relaçôes sociais, a ética não pode ser pensada de forma descontextualizada do modelo social vigente. Nas sociedades primitivas, onde inexistiam a propriedade privada e a divisão em classes sociais, a moral era única, válida para todos e fortemente vinculada com as questōes da natureza. Esta moral 
coletivista e naturalista começou a ser abalada com o gradativo aumento da produção, desencadeadora de uma distribuição desigual dos bens e uma consequente apropriação por alguns do que antes pertencia ao coletivo.

Com a Antiguidade Clássica - período de referência das questôes morais e políticas e de inigualável preocupação com os problemas do homem - emerge uma nítida divisão social: de um lado, os considerados cidadãos gregos, que eram os homens livres; de outro, os escravos, estrangeiros, mulheres e crianças, os quais estavam à margem da sociedade. Tal divisão entre as classes repercutiu também na questão da moral. Havia uma única moral verdadeira, a dos homens livres, onde só importavam os membros da polis grega. Logo, a ação moral se confundia praticamente com a questão da ética e era indissociável da ação política - ressaltese, aqui, ação pertinente apenas aos considerados cidadãos gregos, membros de uma sociedade aristocrática e elitista (FREITAG, 1992).

Seguindo o percurso histórico, cresce o domínio do cristianismo nas sociedades antigas arruinadas pelas guerras, nas quais a escravidão vai sendo gradualmente substituída pelo regime de servidão e a propriedade privada - fenômeno que se evidencia na existência de feudos. São as sociedades medievais, caracterizadas pela estratificação social e pelo monopólio da Igreja nas questôes morais e políticas - e sua correspondente ética cristã, imposta durante dez séculos.

A ética do homem livre vai sendo gradativamente preterida pela formulação metafísica da "salvação humana" a partir da vontade divina, fundada no princípio de que o homem, corrompido pelo pecado original, não conseguiria mais encontrar em si mesmo o caminho da ação correta e justa (LIPOVETSKY, 1994). A partir de então, a moral somente poderia ser encontrada dentro da Igreja. Segundo Vázquez (1984), deve-se ao cristianismo a introdução do princípio moral da igualdade entre os homens, diante de Deus, e a utilização desse mesmo princípio para regular o comportamento do homem e, acrescentamos, para justificar a desigualdade social do período. A ética medieval, subordinada aos dogmas religiosos, caracteriza-se, assim, como teocêntrica e teológica.

A partir da modernidade, lançam-se as bases para uma moral independente dos dogmas religiosos - fundamentos esses iniciados, na verdade, com os filósofos da Grécia antiga, cujas moralidades não implicavam outra autoridade que não a da razão ou da natureza, mas cuja sistematização só veio ocorrer a partir dos pensadores do Iluminismo. O período moderno marca a emancipação da obrigação 
para com Deus e sua substituição pela esfera humana: cabia ao homem alcançar as virtudes por si, sem apoio sobrenatural, pois os deveres para com Deus são ultrapassados pelos deveres para com os outros homens.

No entanto, apesar da ênfase numa moral laica, independente dos laços religiosos, ainda restou como ponto chave a noção de dívida infinita, de dever absoluto para com o outro indivíduo. As obrigações, antes voltadas para o ser superior, voltam-se para outro homem. Lipovetsky (1994) define esse momento como o primeiro ciclo da secularização ética - correspondente aos anos de 1700 a 1950. O imperativo moral é do dever-ser, instituído como tribunal das ações humanas no interior do qual a exigência de felicidade individual foi preterida pelas obrigações da moral social.

O intervalo do século XVI ao início do século XIX compreende, portanto, o período no qual se rejeitou a sujeição da moral à religião. Com as mudanças iluministas nas esferas da economia, com a ascensão do capitalismo; do social, com o desenvolvimento da burguesia; e da política, com a formação de Estados modernos, surgem a ética moderna e, por conseguinte, a perda da fé na religião em nome da fé na razão antropocêntrica. $\mathrm{O}$ salto histórico da modernidade residiu exatamente nos princípios desta ética exclusivamente humana e racional:

Não é a obrigação para com o legislador divino que vai servir de base à organização social e política, mas sim os direitos inalienáveis dos sujeitos. Enquanto o indivíduo se torna o referencial mais importante da cultura democrática, o facto moral primeiro identifica-se com a defesa e com o reconhecimento dos direitos subjectivos; os deveres não desaparecem, derivam dos direitos fundamentais dos indivíduos, tornam-se seus correlativos (LIPOVETSKY, 1994, p. 28).

A partir do fim do primeiro ciclo da moral moderna do dever laico, emerge outro ciclo no qual a ética não somente independe da religião, como também, e principalmente, questiona o próprio dever para com os outros homens. É como se vivêssemos o fim da era do dever e a emergência de uma nova cultura, distante dos mandamentos superiores, dos imperativos e da abnegação, e muito mais próxima do direito individual à satisfação imediata dos desejos. Surge, então, uma sociedade sem nenhuma obrigação nem sanção para com o outro - a não ser para com o próprio indivíduo - denominada sociedade pós-moralista, em que a ideia de sacrifício de si próprio está socialmente deslegitimada, em que a moral já não exige que cada um de nós se dedique a um fim superior a si mesmo, assinala Lipovetsky (1994). 
Caracterizar a sociedade atual como pós-moralista implica dizer que, pela primeira vez e de forma distinta das sociedades modernas erguidas sobre os direitos soberanos dos homens, e que ao mesmo tempo exigiam a obediência incondicional ao dever, a ênfase é no bem-estar individual e na exaltação aos direitos do homem à autonomia e à felicidade plena. Saem definitivamente de cena as formas de autocontrole e os imperativos hiperbólicos do dever, para dar espaço a um individualismo sem regras, no qual as relaçôes entre os homens são pautadas por uma moral sem sacrifícios e, sobretudo, pelo direito à indiferença para com o outro.

Emerge assim uma nova ética, resumida através da seguinte expressão: "mais direito de existência para nós próprios, nenhuma obrigação de nos dedicarmos aos outros". Podemos caracterizá-la como uma ética mínima, na qual não se deixa de auxiliar o outro - o que perdeu legitimidade foi o princípio de viver para o outro. Vale agora o princípio da responsabilidade pós-moralista, o qual nada mais é do que uma tentativa de conciliação dos direitos individuais e das obrigações da vida em sociedade, onde o dever deve estar livre de quaisquer obrigaçôes. Neste período pós-moralista, "dá-se a morte da cultura sacrificial da obrigatoriedade moral nas democracias contemporâneas. [...] Há um regresso da moral da ordem da garantia dos direitos subjetivos, da qualidade de vida e da realização pessoal, mas abandonase a religião do dever" (FREIRE, 2002, p. 116).

O sujeito atual, pós-moderno ou pós-moralista - inserido no tecnicismo e no consumismo do sistema capitalista - tem agora assegurada a justificativa ética do seu egoísmo. O alheamento em relação ao outro passa também a ser um comportamento aceitável, pois a questão da ética na modernidade tardia está configurada como a soberania do eu e tem promovido, consequentemente, o distanciamento para com o outro.

Sabendo, então, que o princípio norteador da ética contemporânea é um olhar para si que perpetua a atitude de afastamento do outro, de indiferença para com ele, como pensar em termos éticos - plano das relaçōes entre pessoas, consideradas sujeitos singulares - numa sociedade onde impera o individualismo, em que o outro só nos interessa enquanto um meio para alcançar nossos objetivos? Como pensar numa ética de abertura ao outro quando as próprias relações entre os homens caracterizam-se mais como relações sujeito-objeto - ou, mais precisamente, relações entre objetos - nas quais a moralidade não consegue dar conta da alteridade? 


\section{Acerca da ética (radical) em Lévinas}

Sabendo não haver uma perspectiva unívoca no estudo da ética, cabe situar o lugar de onde estaremos falando: a ética da alteridade radical, tal como postulada pelo filósofo lituano-francês Emmanuel Lévinas (1906-1995). Seu pensamento nos acompanhará a partir de agora no exercício aqui pretendido, que nos fala sobre a Ética da Alteridade Radical, também denominada Escuta Ética Radical - termos que serão usados indistintamente no decorrer deste texto.

A intenção de Lévinas (1982) não foi construir um sistema ético ou um conjunto de preceitos morais fechados sob a forma de conteúdos dogmáticos. Em lugar disso, Lévinas (1988), ao rejeitar as posições éticas da filosofia tradicional, ambicionou expor de forma absolutamente radical a necessidade de uma discussão ética, de um pensar a partir da ética, melhor dizendo, de uma escuta ética do humano. Sem querer rever teorias já estabelecidas ou complementá-las, o filósofo criou um pensamento original, pois na sua concepção a civilização ocidental falhou na tentativa de dar conta do próprio sentido do humano e do social.

É a partir dessa escuta da alteridade radical que se dá a implicação entre ética e cuidado intencionada neste artigo. ${ }^{1}$ Tal interface não ambiciona impor dogma algum, nem cristalizar conceitos, mas, antes, romper com a ideia de verdade absoluta e com a ordem das coisas já ditas e estabelecidas pela sociedade - ruptura tão enfatizada por Lévinas $(1982,1988)$. Em sua obra, o outro ocupa um lugar essencial, contrastando com certas concepções filosóficas - algumas delas já aqui aludidas - presas ao ser, preocupadas com o sujeito, com sua autonomia e com a satisfação de suas necessidades, preterindo o olhar sobre o outro, o outro em si e a relação intersubjetiva. Tais concepções caracterizam o pensamento da identificação, do poder, da neutralização do outro e da injustiça - mais próximas de verdadeiros impérios do egoísmo e do movimento para si. Por isso, o filósofo põe em questão todo o legado da tradição dominante baseado nos ideais do ser, do poder e do saber, e expõe um novo sentido para o humano, tendo como ponto de partida a experiência originária do encontro humano (PIVATTO, 2000).

O outro não é passível de tematização, nem de conceituação, nem pode mais ser tomado como um objeto conhecido; o outro levinasiano é de uma outra ordem, a qual não cabe numa lógica estritamente racional. A ética em Lévinas não deve, portanto, ser vista sob a óptica (optikê) racionalista, com a qual estamos tão "seguramente" adaptados; ela exige uma outra via: a dos sentidos, a dos afetos e da 
sensibilidade - onde se é afetado pela diferença, pela alteridade, pelo outro. Tratase mais de uma ótica (ótikós), que nos remete à possibilidade da escuta ética.

O outro não pode ser objeto do nosso interesse e sobre ele não deve haver poder, ou seja, nessa perspectiva, não podemos exercer qualquer saber ou domínio. $\mathrm{O}$ ter interesse pelo outro enquanto um objeto implica torná-lo passível de apropriação; em outras palavras, anula-se sua alteridade, transformando-o no mesmo, no idêntico a nós. Da mesma forma, o outro não pode ser objeto, nem deve ser meio para nenhum fim, já que é fim em si mesmo e também deve sê-lo para nós.

Não se trata tampouco de escolher, pois a ética da alteridade radical é da ordem da intimação, da obrigação, a qual é anterior a qualquer acordo. Dito de outro modo, a ética é a questão original, é a filosofia primeira e não mais o ser; logo, o primeiro gesto possível é ético; a primeira fala já é uma resposta: "eis-me”. Em Lévinas (1982, p. 43), encontramos que "a deposição da soberania pelo 'eu' é a relação social com outrem, a relação des-inter-essada. Escrevo-a em três palavras para realçar a saída do ser que ela significa”.

A ética do desinteressamento, em Lévinas (1982, 1988), impede que se tente apropriar-se do outro, de sua alteridade, ou considerá-lo um meio para qualquer fim. Trata-se de se permitir ser afetado, ser desalojado e de acolher o outro em sua exigência por respeito e cuidado. O importante é a evasão de si em favor do outro, uma vez que não se tem como ficar alheio ao novo, ao estranho, à diferença. Assim, a produção de verdades sobre o outro que leva à dogmatização, à rotulação e à cristalização, enfim à anulação da diferença, é o que há de mais distante da proposta levinasiana.

Sua obra nos alerta também quanto à impossibilidade de se fechar ao outro, ao revelar a exigência ética de se deixar afetar pela alteridade, de deixar que a realidade provoque alguma diferença. Eis outra de suas características marcantes: a heteronomia, que rompe com a autonomia típica dos grandes modelos filosóficos, sobretudo os desta contemporaneidade, marcadamente indiferentes ao outro e à alteridade. Deixemos, então, o próprio filósofo expor o seu dizer:

O outro mantém-se e confirma-se na sua heterogeneidade logo que é interpelado, quanto mais não seja para lhe dizer que não se lhe pode falar, para o catalogar como doente, para lhe anunciar a sua condenação à morte; ao mesmo tempo que apanhado, ferido, violentado, ele é 'respeitado'. O invocado não é o que eu compreendo: não está sob uma categoria. É aquele a quem eu falo (LEVINAS, 1988, p. 56). 
Falamos para o outro, que nos intima, provoca, afeta e nos exige uma resposta, ou melhor, uma responsabilidade. Logo, do ponto de vista ético, a preocupação é para com o outro (FREIRE, 2002), para o que a condição ética é a abertura ao outro. $\mathrm{O}$ foco não mais está nas práticas de cuidado de si, como o quer nossa época tardo-moderna, mas sim na disposição de vulnerabilidade e sensibilidade para com o outro. Essa disposição ao outro é o pressuposto de todas as relaçóes sociais. Pressuposto esse que "Se não existisse, nem sequer diríamos, diante de uma porta aberta: 'Primeiro o senhor! '. É um 'Primeiro o senhor!' original que procuro descrever [com a ética da alteridade radical]" (LEVINAS, 1982, p. 81).

A dimensão ética para Lévinas se traduz, conforme já aludido, na responsabilidade de ser por, pelo e para o outro. Estar, portanto, a serviço do outro é a própria moralidade para Lévinas, a qual começa com o acolhimento:

É preciso dispor a escuta para esse outro de forma a responder a ele, ao seu sofrimento (nudez e miséria em Lévinas). Essa resposta é responsabilidade [...]. Oferecer um lugar para o outro - lugar este que desde sempre já seria dele -, abrindo portas e janelas para sua visitação, oferecendo o melhor cômodo e a melhor comida, garantindo-lhe um espaço de habitabilidade, ou seja, um ethos, uma morada confiada e serena onde ele possa renovar-se para retomar suas dores no mundo. (FREIRE, 2003, p. 14).

Acolhimento esse que coloca a relação com o outro fora das dicotomias tradicionais - como, por exemplo, o certo e o errado, o justo e injusto - e no qual a presença do outro, por si só, já traz como intimação o pôr em questão "minha alegre posse do mundo", para usarmos outra expressão levinasiana. E a radicalidade dessa escuta ética está exatamente na afirmação da impossibilidade de se ficar alérgico a outrem! Somente o frente-a-frente da relação com o outro pode curar essa "alergia", pois "O ser que se exprime impõe-se, mas precisamente apelando para mim da sua miséria e da sua nudez - da sua fome - sem que eu possa ser surdo ao seu apelo." (LEVINAS, 1988, p. 179).

Podemos afirmar, sem receio, que na atualidade se é cada vez "mais" indiferente ao outro. Portanto, não se tem aqui a ingenuidade de ignorar que podemos lidar com o outro como um tema, um conteúdo ou como um objeto de nosso interesse e de nossa atuação técnica enquanto profissionais, mas isso nos afasta definitivamente da discussão proposta por Lévinas em sua filosofia social. Nesta, o acesso ao outro é ético, um contato com o verdadeiramente outro, e não mais 
através da anulação da alteridade que ocorre na percepção, no conhecimento ou mesmo no julgamento, que é seu sucedâneo.

Pôr em questão o saber e o poder sobre o outro, sobre as coisas já possuídas e as relações cristalizadas, para que o respeito ao outro em sua diferença permita-nos ouvi-lo em seu sofrer, como, por exemplo, a pessoa enferma na instituição de saúde, não simplesmente como aquele que precisa de um "conserto" ou de um paliativo. É buscar aproximar-se do seu sofrimento, sem anulá-lo ou minimizá-lo, e sim resgatar o que tem de ser a função maior na saúde: o cuidado - não mais o "dever ser", cuja ideia é de normatividade e de obrigação moral.

\section{Ética radical: implicações para o cuidado em Saúde (Coletiva)}

A partir da escuta ética da alteridade radical, consideramos possível aos profissionais que atuam em serviços públicos de saúde, junto ao outro, ir além da tematização, do poder, do saber e do conhecimento sobre o outro tomado como um objeto passível de intervenção tecnicista. Acreditamos ainda ser possível promover a escuta do outro, de outro modo e, assim, assumir a caracterização de um sujeito ético-político. Sujeito esse que busca refletir constantemente sobre suas ações e se deixa afetar pelo outro, tornando-se mais capaz de dar acolhimento e morada - ethos - à alteridade, pois, como já ressaltou Boff (1999), o encontro com o outro promove o ethos necessário à sociabilidade, às relaçoos verdadeiramente humanas.

A importância de resgatar a dimensão ética levinasiana é exatamente essa possibilidade de entender os atores envolvidos na práxis da saúde como sujeitos da responsabilidade pelo outro, de responder ao seu apelo, e do cuidado para com ele. Ao retomarmos o conceito de cuidado - dada sua polissemia -, cabe assinalar que essa categoria é, por vezes mal interpretada ou reduzida em sua amplitude, tal como se evidencia em discussōes levadas a cabo em campos como o da saúde. Tal redução se observa, sobretudo, quando cuidado corresponde a assistência e tratamento, ou seja, se circunscreve a sua dimensão técnica, nivelando-o a cura e controle dos sintomas.

Com efeito, a categoria cuidado também pode ser entendida como assistência - tal como demarcamos em outro estudo recentemente publicado, no qual denominamos "cuidado técnico" práticas desenvolvidas nos serviços de saúde investigados, comprometidas com os modelos tradicionais, a exemplo do modelo 
biomédico e o modo de atenção asilar, ambos focados no "diagnóstico"; na anulação da alteridade e do saber vindo do outro - o usuário, enfatizando o outro como objeto de intervenção tecnicista.

Em relação ao campo da saúde mental, sabemos que a demanda hoje é por uma construção da cidadania dos sujeitos, uma reinserção desses usuários na comunidade ou no território de origem, aumentando sua autonomia e suas interaçôes sociais - pontos basilares da atenção psicossocial, um dos marcos da reforma psiquiátrica brasileira. Nesse sentido, uma definição de atenção psicossocial é encontrada em Silva (2005, p. 144), que a concebe como:

Uma atividade que conta com a contribuição de diferentes saberes e profissionais, como também do saber leigo (mas nem sempre laico) dos familiares e da comunidade (sendo) O principal objetivo dessa modalidade terapêutica [...] aumentar as possibilidades de existência do louco no tecido social, ao mesmo tempo em que procura minimizar o sofrimento psíquico. Para tanto, cuida-se do usuário, convocando à responsabilidade aqueles que o cercam, no sentido de que a dependência institucional diminua e os "laços sociais" aumentem. Paulatinamente, procura-se "engajar", "implicar" e "vincular" atores sociais diversos na tarefa de cuidar.

Compreendida sob um ângulo mais pragmático, depreende-se que a noção de atenção psicossocial conflui para a categoria cuidado em sua dimensão técnica. Contudo, cabe ressaltar que "cuidado", no âmbito da discussão aqui empreendida, se volta para sua dimensão ontológica, constitutiva da condição de aparecimento, do modo de ser-no-mundo, distanciando-se de acepções mais pragmáticas, tais como as demarcações efetuadas nos conceitos de atenção e assistência. Portanto, abordar o cuidado como uma escuta ética implicar ir além e redimensionar a atuação do profissional de saúde a partir de uma atitude de resposta à necessidade do outro (quer seja o louco destituído de sua condição de sujeito ou o usuário internado num serviço não-psiquiátrico, muitas vezes reduzido a um número de leito ou de prontuário). Tal resposta, ou nos termos levinasianos, tal responsabilidade para com o outro, precisa ser dada pelos profissionais no cotidiano da práxis na saúde (coletiva). Para tanto, há que ter uma abertura ao encontro com o outro, caso se assuma a postura de "estar em relação", de "ser para" o outro.

Buscamos, na discussão empreendida, ressaltar que a maior implicação do cuidado como dimensão ética é o serviço ao outro de forma "desinteressada", conceito filosófico que se redefine no pensamento de Lévinas (1982, 1988) 
expressando que o outro, em sua alteridade, não pode ser um meio qualquer que seja o fim. Isso impõe que o profissional, em sua práxis na saúde, se permita ser afetado, ser desalojado de seu saber-poder para, então, poder acolher quem a ela acorre em sua exigência ética por respeito e cuidado. Em recente artigo, Nunes et al. (2008, p. 195) problematizam também que considerar a dimensão do cuidado no trabalho clínico configura o que as autoras definem como "[...]uma 'clinica do encontro', pautada no diálogo, na escuta interessada, na produção de intersubjetividades, na troca, na partilha".

Desse modo, e esta foi a motivação do artigo, consideramos premente insistir na discussão da categoria cuidado, reiteramos, em sua dimensão ontológica, considerando-a a partir do encontro intersubjetivo, não reduzido, portanto, à intervenção técnica (mas sem negá-la) ou ao saber-poder sobre o outro, comprometidos com uma ortopedia ou controle. Reconhecido como um desafio à organização dos serviços públicos de saúde do país (AYRES, 2005), o cuidado nesta acepção ética - abre a possibilidade de o profissional da saúde assumir uma nova atitude de inter-ação, de criação, de não-conformação aos saberes instituídos e cristalizados, de busca por novos diálogos, de desinteressamento, nos termos de Lévinas e, sobretudo, de contínua reflexão crítica sobre seu modo de estar a serviço do outro - no caso, o usuário dos sistemas de saúde.

A maior implicação do cuidado como uma dimensão ética é, por conseguinte, o serviço ao outro de forma "desinteressada", ou seja, sem intenção de transformálo no mesmo ou em algo da ordem das coisas já estabelecidas, passíveis de uma intervenção técnica ou de uma prática de controle e ajustamento - e onde o outro é compreendido como objeto de estudo e intervenção. Cuidar, então, precisa ser "mais que um ato, é uma atitude. Portanto, abrange mais que um momento de atenção, de zelo e de desvelo. Representa uma atitude de ocupação, preocupação, responsabilização e de envolvimento afetivo com o outro.” (BOFF, 1999, p. 33). O cuidado é o sentido original do humano, é constitutivo da sua natureza, o que levou esse mesmo autor a caracterizá-lo como um modo-de-ser essencial.

O cuidado como dimensão ontológica foi trabalhado na obra de Heidegger (1997). Para ele, o cuidado ou "cura" se dá como um testemunho pré-ontológico da presença originária. O cuidado é visto, então, como inerente à existência humana, como um "artesão" da construção sempre em curso dessa existência, conforme assinalado por Ayres (2004). Portanto, e mais uma vez, constatamos que a relação 
com o outro suscita responsabilidade. A condição originária de nossa subjetividade, a responsabilidade pelo outro, manifesta-se através do nosso modo de agir e de interagir com o outro, pois, como ressaltou Gadamer (2002), a arte de curar não inclui apenas o bem-sucedido combate à doença, mas principalmente o cuidado da saúde.

A dimensão ética do cuidado (CARVALHO; BOSI; FREIRE, 2008) não implica somente a rejeição ao uso da técnica ou do necessário controle da doença, da queixa ou do desconforto que levam o usuário ao serviço de saúde. Abordar o cuidado como uma escuta ética demanda ir além e redimensionar a atuação do profissional de saúde a partir de uma atitude de resposta à necessidade do outro. Essa resposta, ou nos termos levinasianos, essa responsabilidade para com o outro, pode ser dada pelos profissionais no cotidiano da práxis na saúde (coletiva). Para tanto, há que ter uma abertura ao encontro com o outro, caso se assuma a postura de "estar em relação", de "ser para" o outro, e desenvolva um serviço que responda à exigência por respeito aos sentimentos, escuta de seu sofrimento e acolhimento de sua singularidade, seus desejos, saberes e história de vida.

Essa abertura ao outro demanda ainda uma prática não restrita ao saber técnico e que, ao se deparar com o outro, possa construir um saber peculiar que dê conta dos meios e dos fins de sua ação na área da saúde: o saber ético (GADAMER, 2002). Senão, caracterizará o que Boff (1999) denominou de modo-de-ser-trabalho, cuja postura é a de intervenção e de uso do poder e do conhecimento sobre o outro, tratado como objeto.

\section{Considerações finais}

Consoante o exposto sobre a escuta ética, o lugar dos profissionais atuantes no âmbito da saúde (coletiva) não se restringe às competências e intervenções técnicas, nem tampouco sua atuação nos serviços de saúde revela-se como um conjunto de relações estáticas, individualizadas e individualizantes. A atitude de cuidado ultrapassa o foco da subjetividade para o da intersubjetividade, no qual se é afetado pela alteridade, pelo discurso e saber vindos do outro, no caso, os usuários dos serviços.

Os desafios que ora se colocam para a área da saúde (coletiva) impõem que o cuidado se caracterize como a tarefa orientadora de todos os profissionais envolvidos no cotidiano da produção do cuidado, pois "Cuidar da saúde de alguém é mais 
que construir um objeto e intervir sobre ele. Para cuidar há que se considerar e construir projetos. A atitude 'cuidadora' precisa se expandir mesmo para a totalidade das reflexões e intervenções no campo da saúde” (AYRES, 2001, p. 71).

A arte da assistência à saúde não pode reduzir-se à mera manipulação de objetos. É preciso articular a intervenção técnica com outros fatores não-tecnológicos, já que nossa presença junto ao outro jamais se resumirá à presença diante de um artefato tecnológico. A implicação dessa questão é, no espaço focalizado neste artigo, os profissionais colocarem seu papel de perito em xeque (FREIRE, 2003) e ousarem romper com os modelos tradicionais de assistência limitados a posturas de tratamento, controle e "cura", buscando pautar sua prática por outro modo de atenção, que dê conta do acolhimento e do cuidado para com o sujeito doente, usuário do serviço.

Comprometidos dessa forma com o respeito e o acolhimento da diferença, a práxis em saúde resgata a dimensão ética do cuidado aproximando-se da escuta ética levinasiana, retomando o sentido originário de sua atuação: o cuidado. Desse modo, pauta sua atuação com o modo-de-ser-cuidado (BOFF, 1999), que é a relação entre sujeito e sujeito, orientada não pelo domínio "sobre", mas pela "interação" e "con-vivência", e não mais pela relação sujeito-objeto:

Cuidar das coisas [não só o homem] implica ter intimidade, sentí-las dentro, acolhê-las, respeitá-las, dar-lhes sossego e repouso. Cuidar é entrar em sintonia com, auscultar-lhe o ritmo e afinar-se com ele. A razão analítico-instrumental abre caminho para a razão cordial, o esprit de finesse, o espírito de delicadeza, o sentimento profundo. A centralidade não é mais ocupada pelo logos razão, mas pelo pathos sentimento" (BOFF, 1999, p. 96 - grifos no original).

O cuidado surge como uma crítica e como uma nova "tecnologia", apontam os autores Pinheiro e Guizardi (2005), capaz de romper o discurso hegemônico da racionalidade médica e de dar conta da demanda por uma integralização da assistência. Integralidade essa que se coloca como um dispositivo político com implicações no espaço da intersubjetividade, significando dizer que, como uma prática social, busca reconhecer as diferentes visões de mundo, saberes e diálogos próprios ao campo da saúde. Em Ayres (2005), o cuidado é considerado como um desafio à organização dos serviços públicos de saúde do país.

Não por acaso, o debate atual sobre a qualidade da atenção na saúde e sobre a implantação da política de humanização nos serviços tem como principais pontos 
a produção de cuidados, a valorização do protagonismo dos profissionais e dos pacientes e o respeito à diferença. A reconstrução das práticas de saúde, a partir da humanização da assistência, somente será possível se antes os próprios profissionais passarem por um processo de reflexão crítica e de abertura à presença do outro - os quais consideramos como elementos-chave para a exigência ética de uma atitude de cuidado para com o outro (BOSI; UCHIMURA, 2006; CARVALHO; BOSI; FREIRE, 2008).

Há urgência por uma "nova cultura de atendimento" no campo da saúde. Diremos aqui de outro modo: há urgência de uma nova atitude de cuidado para com o outro, que se abra ao encontro e ao diálogo com a alteridade, seja a das várias profissões atuantes no setor, seja a do próprio usuário. As políticas públicas precisam também se voltar para a própria realidade dos serviços e das condiçóes de trabalho. Assim, a política de humanização da assistência, mais do que uma política marcada por princípios legais, assume também o significado de uma ação preocupada com os modos de vida dos atores do setor e aborda os discursos e poderes nas práticas de saúde.

Sair da intervenção tecnicista, do saber-poder sobre o outro, de anulação da diferença, da relação sujeito-objeto para uma nova atitude de inter-ação, de relação intersubjetiva, de "ser para" e de responder à exigência do outro por respeito e cuidado, pode, sim, caracterizar a humanização da assistência e o cuidado integral nas ações e serviços de saúde. Cuidado para com o outro concretizado através de atitudes de respeito, escuta e acolhimento da sua singularidade e de seu sofrimento. Essa tarefa não implica a negação dos saberes e conhecimentos já construídos no campo da saúde, mas, antes, a necessidade de expansão das ações rumo ao diálogo para podermos, de fato, caminhar em direção à melhoria do cuidado no campo dos serviços públicos de saúde.

\section{Referências}

AYRES, J. R. C. M. Cuidado e reconstrução das práticas de saúde. Interface-Comunic, Saúde Educ, v. 8, n. 14, p. 73-92, 2004.

. Hermenêutica e humanização das práticas de saúde. Ciênc Saúde Coletiva, v. 10, n. 3, p. 549-60, 2005.

. Sujeito, intersubjetividade e práticas de saúde. Ciênc Saúde Coletiva, v. 6, n.1, p. 63-72, 2001.

BOFF, L. Saber cuidar: ética do humano - compaixão pela terra. Petrópolis: Vozes, 1999. 199 p. 
BOSI, M. L. M.; UCHIMURA, K. Y. Avaliação qualitativa de programas de saúde: contribuições para propostas metodológicas centradas na integralidade e na humanização. In: BOSI, M. L. M.; MERCADO, F. J. (Org.). Avaliação qualitativa de programas de saúde: enfoques emergentes. Petrópolis: Vozes, 2006. p. 87-117.

CARVALHO, L. B.; BOSI, M. L. M.; FREIRE, J. C. Dimensão ética do cuidado em saúde mental na rede pública de serviços. Rev Saúde Pública, v. 42, n. 4, p. 700-706, 2008.

ECO, U. Quando o outro entra em cena nasce a ética. In: ECO, U.; MARTINI, C. M. (Org.). Em que creem os que não creem? Rio de Janeiro: Record, 2000.

FREIRE, J. C. A psicologia a serviço do outro: ética e cidadania na prática psicológica. Psicol Ciênc Prof, v. 23, n.4, p. 12-15, 2003.

. O lugar do outro na modernidade tardia. São Paulo: Anablume, 2002. 166 p.

FREITAG, B. Intinerários de Antígona: a questão da moralidade. Campinas: Papirus, 1992.

GADAMER, H-G. Mistério da saúde. In: GADAMER, H-G. O mistério da saúde: o cuidado da saúde e a arte da medicina. Lisboa: Edições 70, 2002. p. 101-111.

HEIDEGGER, M. A cura como ser da pre-sença. In: Ser e tempo. Petrópolis: Vozes, 1997. p. 243-300.

LEVINAS, E. Ética e infinito. Lisboa: Edições 70; 1982.

. Totalidade e infinito. Lisboa: Ediçōes 70; 1988.

LIPOVETSKY, G. O crepúsculo do dever: a ética indolor dos novos tempos democráticos. Lisboa: Publicações Dom Quixote; 1994.

MEZAN, R. O psicanalista como sujeito moral. In: FRANÇA, Maria I. (Org.). Ética, psicanálise e sua transmissão. Petrópolis: Vozes, 1996. p. 122-135.

NUNES, M. et al. A dinâmica do cuidado em saúde mental: signos, significados e práticas de profissionais em um Centro de Assistência Psicossocial em Salvador, Bahia, Brasil. Cad. Saúde Pública, Rio de Janeiro, v. 24, n. 1, p. 188-196, jan. 2008.

PIATTO, P. S. Ética da alteridade. In: OLIVEIRA, M. A. (Org.). Correntes fundamentais da ética contemporânea. Petrópolis: Vozes, 2000. p. 79-97.

PINHEIRO, R.; GUIZARDI, F. L. Cuidado e integralidade: por uma genealogia de saberes e práticas no cotidiano. In: PINHEIRO, R.; MATTOS, R. A. (Org.). Cuidado: as fronteiras da integralidade. 2. Ed. Rio de Janeiro: Cepesc; 2005. p. 21-36.

SILVA, M. B. B. Atenção psicossocial e gestão de populações: sobre os discursos e as práticas em torno da responsabilidade no campo da saúde mental. Physis: Rev. Saúde Coletiva, Rio de Janeiro, v. 15, n. 1, p. 127-150, 2005.

VÁZQUEZ, A. S. Ética. 7. Ed. Rio de Janeiro: Civilização Brasileira, 1984. 


\section{Nota}

${ }^{1} \mathrm{O}$ presente artigo é resultado de dissertação de mestrado defendida pela primeira autora, sob a orientação dos demais autores. Não há conflitos de interesse envolvidos no mesmo. Carvalho, Freire e Bosi participaram igualmente de todas as etapas de elaboração do texto. 
Abstract

\section{Radical Ethics: Implications on Health Care}

This paper intends to discuss ethics and care, its mutual relation and the implications of these concepts in the praxis developed in the public health services. So the authors adopted Emmanuel Lévinas's contributions as central reference in this essay. This discussion seems useful for a broader and deeper understanding of this practice, to (re)construct it from an ethical-political perspective, based on the dimension of the ethical listening of the care for the other: in this case, the user of health services.

Key words: ethics; care; Public Health; health professionals; Lévinas. 